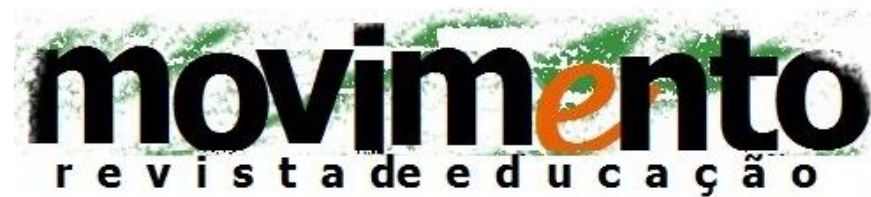

faculdade de educação - programa de pós-graduação em educação

universidade federal fluminense

issn 2359-3296

ano 3 número $4-2016$

\section{UMA RETROSPECTIVA DA FORMAÇÃO DE PROFESSORES: histórias e questionamentos}

\author{
Michele Guedes Bredel de Castro1
}

\section{RESUMO}

O debate sobre a profissionalização docente não é recente, e nas últimas décadas se intensificaram devido às iniciativas de reestruturação curricular dos cursos de licenciatura. O presente trabalho procurará apresentar uma síntese histórica da evolução da profissão docente, perpassando pelo ensino na colônia, o ensino Normal (a feminização e desvalorização do Magistério), o docente da educação infantil e séries iniciais do ensino fundamental, bem como a situação atual frente à LDB. Defini como metodologia uma pesquisa de cunho teórico. Tomei como referencial teórico dentre outros autores, os estudos de Marques (2000), Nóvoa (1991, 1992, 1995), Tanuri (2000).

PALAVRAS-CHAVES: formação docente, história da educação, professores da educação infantil.

\section{ABstract}

The debate on teacher professionalization is not new, and in recent decades have intensified due to the curricular restructuring initiatives of Normal Schools and pedagogy courses, from the experiences of new training courses in higher education. This paper seeks to provide a historical overview of the development of the teaching profession, passing by the school in the colony, the Normal school (the feminization and devaluation of the Magisterium), teachers of kindergarten and early elementary school grades, as well as the current situation facing the LDB. Set as methodology one

1 Doutora em Educação (UFF). Realiza estágio pós-doutoral em educação na UFES. michelebredel@gmail.com 
theoretical, research. I like theoretical framework among others, studies of Marques (2000), Nóvoa (1991, 1992, 1995), Tanuri (2000).

KEYWORDS: Teacher professionalization, History of education, Childhood education, teacher

\begin{abstract}
Não há ensino de qualidade, nem reforma educativa, nem inovação pedagógica, sem uma adequada formação de professores. Esta afirmação é de uma banalidade a toda prova. E, no enquanto, vale a pena recordá-la num momento em que o ensino e os professores se encontram sob fogo cruzado das mais diversas críticas e acusações. (Nóvoa, 1992, p.17)
\end{abstract}

\title{
INTRODUÇÃo
}

Falar de formação de professores é falar de algo tão antigo quanto atual, tão explorado quanto desconhecido, tão banal quanto fundamental - substantivos que se contrapõem e ao mesmo tempo se completam, apontando um caminho tortuoso. O debate sobre a profissionalização docente não é recente, e nas últimas décadas se intensificou devido às iniciativas de reestruturação curricular das escolas normais e dos cursos de pedagogia, com as experiências de novos cursos de formação em nível superior e também com a produção acadêmica intensa sobre o assunto (Silva, 1991), principalmente a literatura de autores portugueses e espanhóis acerca da tradição acadêmica da formação docente. Esse debate acentua-se com a aprovação da Lei de Diretrizes e Bases - Lei 9394/96 - que, superando a polêmica relativa ao nível de formação, elevou a formação do professor das séries iniciais ao nível superior, estabelecendo que ela se daria em Universidades e em Institutos Superiores de Educação, nas licenciaturas e em cursos normais superiores. Os tradicionais cursos normais de nível médio foram apenas admitidos como formação mínima (art. 62):

A formação de docentes para atuar na Educação Básica far-se-á em nível superior, em curso de graduação plena, em universidades e institutos superiores de educação, admitida, como formação mínima para o exercício do magistério na educação infantil e nas quatro primeiras séries do ensino fundamental, a oferecida em nível médio, na modalidade Normal. 
Esse artigo aponta para uma formação mínima em nível médio, contudo nas Disposições Transitórias da LDB, o art. 87, \$ $4^{\circ}$ dia: "Até o fim da Década da Educação somente serão admitidos professores habilitados em nível superior ou formados por treinamento em serviço". Com isso, pode-se constatar que o nível médio será de caráter transitório até que todos possam ter curso superior. Acreditando que os problemas da formação docente hoje têm raízes no passado, ou seja, no mestre-escola de outrora. São de suma importância o resgate e a construção da informação histórica, na expectativa de que ela possa oferecer subsídios que possibilitem a melhor compreensão da problemática da Escola Normal e das questões atuais sobre a formação do professor, em especial o que atua nas séries iniciais do ensino fundamental e educação infantil.

Nóvoa (1995, p.14) complementa as colocações acima dizendo: "o processo histórico de profissionalização do professorado (passado) pode servir de base à compreensão dos problemas atuais da profissão docente (presente) ".

Cumpre ressaltar, que o presente trabalho procurará apresentar uma síntese histórica da evolução da profissão docente, perpassando pelo ensino na colônia, o ensino Normal (a feminização e desvalorização do Magistério), o docente da educação infantil e séries iniciais do ensino fundamental, bem como a situação atual frente à LDB. Portanto, buscaremos historicizar o processo pelo qual se constituiu a profissionalidade do professor na dinâmica de nossa sociedade, entrecruzando com os acontecimentos atuais. Para isso, defini como metodologia uma pesquisa de cunho teórico. Tomei como referencial teórico dentre outros autores, os estudos de Marques (2000), Nóvoa (1991, 1992, 1995), Tanuri (2000).

\section{A EdUCAÇÃo NA COLÔNIA}

Considerando a impossibilidade de tentar compreender o sistema educacional - formação docente e assuntos correlacionados - sem remetermos a matriz de 
nossa sociedade ${ }^{2}$, passamos agora a discorrer suscintamente a respeito de nossa raiz embrionária, quer dizer, a educação deste o início do nosso descobrimento, pois boa parte de nossas questões - não somente educacionais - nascem no período colonial e se agrava ao longo dos anos e séculos.

Em 1549, chegam ao Brasil os padres jesuítas, com eles têm-se o início da história da educação em nosso país. Durante dois séculos - XVI e XVII - eles foram praticamente os nossos únicos educadores. Transmitiram segundo Azevedo (1963, p.93), "quase na sua integridade, o patrimônio de uma cultura homogênea, a mesma língua, a mesma religião, a mesma concepção de vida e os mesmos ideais de homem culto". Através da obra de educação popular, nos pátios de colégios ou em aldeias, eles formaram e organizaram os fundamentos do nosso sistema de ensino.

Assim, durante os 210 anos em que permaneceram no Brasil, os jesuítas exerceram uma poderosa influência que se registrou na formação da sociedade brasileira e se constituíram nos principais, senão os únicos, mentores intelectuais e espirituais da colônia. Apresentando um ensino medido, dosado mas nitidamente abstrato, dogmático, memorístico, repetitivo, livresco e verbalista - exerceram papel conservador, tornando a cultura "sem pensamento e sem substância”. (Ferreira, 2000; Ribeiro, 1995).

A educação feminina nesta época era restrita às boas maneiras e às prendas domésticas e à elite cabia à preparação para o trabalho intelectual segundo o modelo religioso. Em relação aos professores, que eram considerados aptos para exercer o magistério somente aos trinta anos, os jesuítas dedicavam atenção especial ao seu preparo: selecionavam cuidadosamente os livros e exerciam rigoroso controle sobre as questões a serem suscitadas pelos professores, especialmente em filosofia e teologia.

Na primeira metade do século XVIII, o trabalho educacional e de catequese da Companhia de Jesus entra em decadência, devido à acusação de ser um

2 Também levando em conta que não se estuda educação quer na Colônia, quer na República, desvinculada da sociedade. 
empecilho à conservação da unidade cristã e da sociedade civil. Ela era detentora de um poder econômico que deveria ser devolvido ao governo e educava o cristão a serviço da ordem religiosa, e não dos interesses do país (Ribeiro, 1995; Ferreira, 2000).

Assim, em 1759 aqueles são expulsos de Portugal e de suas colônias e, consequentemente do Brasil. Desmanchando o sistema de ensino que havia sido construído em dois séculos.

OS PRIMÓRDIOS DA PROFISSÃO DOCENTE: as primeiras iniciativas

Ao final de três séculos de colonização portuguesa nosso país mostra no campo educacional as marcas do projeto levado a cabo por Portugal. A expulsão da Companhia de Jesus dos domínios portugueses, após séculos de predominância na nossa educação dá início a um processo de laicização da instrução com o envio dos professores régios. A esse respeito Nóvoa (1995. p.15) ressalta "o processo de estatização do ensino consiste, sobretudo, na substituição de um corpo de professores religiosos (ou o controle da Igreja), por um corpo de professores laicos (ou sob o controle do Estado), sem que, no entanto, tenha havido mudanças significativas nas motivações, nas normas e nos valores originais da profissão docente: o modelo do professor continua muito próximo do padre".

Portugal, apesar de pioneiro nas reformas de laicização do sistema escolar adentra o oitocentos com um sistema bastante precário de instrução. Embora imerso num processo mais lento em relação à maioria de seus vizinhos, desenvolveria nessa mesma época uma política de consolidação de um sistema estatal de instrução.

Villela (200, p.98) destaca algumas medidas em relação à instrução primária que passaram a ser desenvolvidas: "unificar o sistema por meio de adoção de um método, definição de conteúdos de ensino, autorização ou proibição de livros, estabelecimento de normas burocráticas a serem seguidas pelas 
escolas". Essas medidas tinham a intenção de estabelecer homogeneidade e tornar estatal um sistema característico pela diversidade, já que a imersão dos indivíduos na cultura letrada se fazia por iniciativa da família, igreja, preceptores particulares, corporações profissionais, associações filantrópicas, dentre outras.

Quanto à Colônia, algumas medidas foram tomadas em relação à instrução com a transferência da Família Real e sua Corte há uma aceleração de um processo que já se encontrava em andamento - sobretudo em relação à instrução em nível superior. As medidas relativas à organização da instrução elementar foram mais tímidas, ficando por muito tempo esse nível restrito à esfera privada, ou seja, por conta das famílias. Assim como na Europa, aqui àquela época, haviam inúmeras formas e locais de ensinar e aprender: "nas grandes propriedades rurais, padres ligados aos engenhos ensinavam filhos de fazendeiros, agregados e até escravos. Nos espaços urbanos a diversidade era maior, variando de acordo com as posses e os objetivos das famílias" (Villela, 2000, p.99).

Formas dispersas de ensino e aprendizagem coexistiram por muito tempo. No decorrer de três séculos a função docente, de início não era especializada e exercida como ocupação secundária, conforme Nóvoa (1995, p.15) enfatiza:

[...] a função docente desenvolve-se de forma subsidiária e não especializada, constituindo uma ocupação secundária de religiosos ou leigos das mais diversas origens. A gênese da profissão de professor tem lugar no seio de algumas congregações religiosas, que se transformaram em verdadeiras congregações docentes. Ao longo dos séculos XVII e XVIII, os jesuítas e os oratorianos, por exemplo, foram progressivamente configurando um corpo de saberes e de técnicas e um conjunto de normas e de valores específicos da profissão docente.

Contudo a função docente vai mudar radicalmente e começam as primeiras iniciativas para organizar um sistema de instituição primária, percebe-se a manutenção das formas e dos modelos escolares elaborados sob a tutela da Igreja, aos quais se justapõe um novo "corpo de docentes", recrutados e vigiados pelas instâncias emanadas do poder estatal. 
Segundo Nóvoa (1991), a gênese da profissão docente é anterior à estatização da escola, pois, desde o século XVI, já existiam vários grupos de leigos e religiosos, que se dedicavam à atividade docente, mas como vimos com o envio dos professores régios portugueses inicia-se uma organização e normatização do exercício da profissão docente, porém somente após a Lei Geral do Ensino de 1827 que a intervenção estatal se efetivará quanto à organização dos professores.

Segundo Tanuri (2000), o estabelecimento das Escolas Normais destinadas ao preparo específico dos professores está ligado à institucionalização da instrução pública. É com a Revolução Francesa que se concretiza a ideia de uma Escola Normal a cargo do Estado destinada a formar professores leigos. Antes, porém que se fundassem as primeiras instituições destinadas a formar professores para as escolas primárias, já existiam preocupações no sentido de selecioná-los. A Lei de 15/10/1827, que mandava criar escolas de primeiras letras em todas as cidades, vilas e lugares mais populosos do Império, também estabelecia exames de seleção para mestres.

A primeira forma de preparação de professores deu-se nas primeiras escolas de ensino mútuo, instaladas a partir de 1820 , no Brasil. Havia a preocupação não somente de ensinar as primeiras letras como também de preparar docentes, instruindo-os no domínio do método. Algumas decisões posteriores indicam que o objetivo era instruir pessoas acerca do método Lancaster ${ }^{3}$.

A partir da influência do pensamento iluminista no plano pedagógico passa-se a crença de que "um país é o que a sua educação o faz ser", sendo assim, o ensino ou "luzes", como era dito nesse período, forma no contexto desse ideário de popularização do ensino, as escolas normais (Barros, 1986).

3 "O método lancasteriano procurava, entre outras coisas, desenvolver principalmente os hábitos disciplinares de hierarquia e ordem, exercendo um controle pela suavidade, uma vigilância sem punição física. Tais características se encaixavam perfeitamente nos propósitos políticos do grupo conservador" (Villela, 2000, p. 107). 
Paralelamente à valorização das escolas normais, ocorre também o enriquecimento de seu currículo, ampliação dos requisitos para ingresso e sua abertura ao elemento feminino ${ }^{4}$.

No que tange ao currículo, este quase não se diferenciava do das escolas primárias, a não ser pela parte metodológica, já que os futuros mestres deveriam dominar teórica e praticamente o método lancasteriano. Não havia intenção de oferecer ao futuro mestre uma formação mais aprofundada em termos de conteúdo, enquanto a formação moral e religiosa era muito enfatizada.

Para admissão nas escolas normais, o documento legal de criação da Escola Normal de Niterói estabelece: boas condições morais do indivíduo, portanto era necessário boa morigeração ${ }^{5}$. Além de saber ler e escrever, dentre outros critérios como evidenciados no art 4\%: "Para ser admitido a matricula na Escola Normal requer-se: ser cidadão brasileiro, maior de dezoito anos, com boa morigeração; e saber ler e escrever"6.

As primeiras escolas normais eram destinadas apenas aos elementos do sexo masculino, excluindo o sexo feminino. Aliás, mecanismos de exclusão do saber refletiam-se descaradamente no currículo, que para o sexo feminino era mais reduzido e diferenciado, contemplando o domínio de trabalhos domésticos. Durante todo o século XIX, veremos firmada essa diferenciação nos currículos tanto das primárias femininas, quanto nas seções femininas das escolas normais, na qual o ensino das disciplinas da área de exatas era ausente.

Somente no final do século, com a experiência da co-educação, num momento em que o número de mulheres superava o de homens, vamos ter um currículo unificado. Porém, disciplinas como matemática nunca seria dada com nível de profundidade igual. E até hoje essa atitude é percebida nos cursos normais

\footnotetext{
${ }^{4}$ Mesmo com a presença feminina nos colégios de profissionalização docente, o ensino não é dado de forma mista, ou seja, homens e mulheres são separados por escolas, salas, turnos e até por dias alternados.

${ }^{5}$ Boa morigeração relacionava-se à moral, bons costumes, boa educação (Villela, 2000, p.).
} 
secundários - nível médio - que ainda existem. Foi dada uma importância menor às disciplinas da área de exatas, tanto por parte dos alunos que se dizem incapazes de assimilar tais conteúdos, como dos professores que selecionavam os conteúdos mais fáceis e superficiais de disciplinas como física, química, matemática, geometria.

Até o final do século sucederam-se pequenas reformas na Escola Normal que não mudaram em essência o caráter das disciplinas do curso. $O$ advento do novo regime não trouxe alterações significativas para a instrução pública, nem inaugurou uma nova corrente de ideias educacionais, tendo o quadro social, político e econômico da Primeira República pouco favorecido à difusão do ensino.

Nos primeiros anos da República é importante destacar a influência das filosofias cientificistas e a introdução dos primeiros ensaios de renovação pedagógica no ensino público, ressaltando-se o valor da observação, da experiência sensorial, da educação dos sentidos, das "lições de coisas", do método intuitivo de Pestalozzi. Assim, a reforma paulista realizada sob a direção de Caetano Campos, ampliou a parte propedêutica do currículo da Escola Normal e contemplou as suas escolas-modelos anexas, bem como a prática de ensino que os alunos aí deveriam realizar.

Foi proposto pelos reformadores republicanos paulistas entre outras metas 0 dos cursos complementares, com o objetivo de integralizar o primário; entretanto, isso não ocorreu, mas sim o objetivo adicional de preparar professores para as escolas preliminares, mediante apenas o acréscimo de um ano de prática de ensino nas escolas modelos. Consolidando-se assim um dualismo: escolas complementares em escolas normais primárias, e denominadas as de padrão mais elevado de "normais secundárias", alcançando um ensino de tipo único, pelo menos para maioria dos estabelecimentos.

${ }^{6}$ Coleção de Leis, Decretos e Regulamentações. Lei № 10, de 04/04/1835, Art 4ํ. (Apud Villela, 2000, p.106). 
A propósito dos cursos complementares Tanuri (200, p.69-70) destaca:

Apesar das tentativas realizadas no início da República para a implantação de um ensino primário de longa duração (oito séries), dividido em dois ciclos - elementar e complementar ou superior - e, calcado em modelos europeus, foi somente a partir da segunda década do presente século (1900) que os estados brasileiros começaram a instalar cursos complementares em continuação ao primário, destinados a funcionar como curso geral básico, de preparação para a escola normal, justapondo-se paralelamente ao secundário. Nestas condições, introduzia-se em nosso sistema de ensino uma bifurcação nos estudos gerais imediatamente após a escola primária (...). A criação do curso complementar estabelecia um elo de ligação entre a escola primária e a normal e o ingresso na última passava a exigir maiores requisitos de formação".

Por toda década de 1920 há uma preocupação e entusiasmo pela problemática educacional. A divulgação dos princípios e fundamentos escolanovistas fundamentam as reformas estaduais do ensino primário e normal, fornecendo elementos para uma revisão crítica dos padrões de escola normal existente. $\mathrm{Na}$ expressão de Nagle $(1990,264)$, ao "entusiasmo pela educação" sucede o "otimismo pedagógico". Neste momento, já não importa muito qualquer esforço para difundir a escola - entusiasmo - pois o que mais importa é difundir a escola que reproduz um novo modelo - otimismo.

Nessas condições consolida-se nesse período a ideia de desdobramento dos estudos propedêuticos e profissionais, em dois cursos distintos; a criação ou ampliação dos estudos complementares, preparatórios ao normal; e em alguns estados, a divisão do curso normal em dois ciclos: um geral ou propedêutico e outro especial ou profissional.

É importante destacar que a introdução de escolas normais de iniciativa privada e municipal, qualificadas de livres ou equiparadas, com o que se procurava compensar a escassez de estabelecimentos, também contribuiu para a expansão da Escola Normal. Aliás, desde o período imperial já estava assegurado a liberdade de ensino e permanecia na Carta Magna republicana em decorrência do art. 72, parágrafo 24, o "livre exercício de qualquer profissão 
moral, intelectual e industrial" (Apud Tanuri, 2000, p.71). Na verdade, essas escolas normais particulares existiram desde o Império.

A partir de 1930, o país passa por profundas transformações políticoeconômicas e sociais. Com a crise internacional da economia, a sociedade que se pautava no modelo agrário-rural urbaniza-se e industrializa-se, ocorre a aceleração do capitalismo industrial e a introdução de novas formas de produção, gerando cada vez mais a necessidade de os operários terem um mínimo de instrução para operar as máquinas. Nesse período, destaca-se também o papel dos intelectuais educadores na luta pela expansão da escolaridade. Os pioneiros da educação nova vinham lutando, desde a década de 20, por uma escola pública gratuita para todos; visto que o que predominava na manutenção das escolas era o das ordens religiosas, que mantinham escolas pagas. As palavras chaves dessa época eram: escola nova, ensino ativo, método analítico, testes e medidas. A literatura pedagógica, até então voltada quase que exclusivamente para uma abordagem ampla dos problemas educacionais, de uma perspectiva social e política, passa a tratar os problemas educacionais de um ponto de vista técnico, "científico", contemplando desde questões teóricas e práticas do âmbito intra-escolar, até abordagens pedagógicas mais amplas da perspectiva da escola renovada.

Fernando de Azevedo elabora e 26 educadores brasileiros, líderes do movimento de renovação educacional, assinam o Manifesto dos Pioneiros da Educação Nova. Publicado em 1932, representou o auge da luta ideológica. Entre as reivindicações contidas nele encontramos a solicitação de autonomia para a função educativa e a descentralização do ensino. Para eles a organização do sistema escolar devia visar obter uma ação unificadora. Assim encontra-se descrito no Manifesto:

A seleção dos alunos nas suas aptidões naturais, a supressão de instituições criadoras de diferenças sobre base econômica, a incorporação dos estudos do magistério à universidade de mestres e professores em remuneração e a reação contra tudo que lhe quebra a coerência interna e a unidade vital, constituem o programa de uma política educacional, fundada sobre a aplicação do princípio unificador, que modifica profundamente a estrutura íntima e a 
organização dos elementos constitutivos do ensino e dos sistemas escolares (apud, Romanelli, 1984, p. 148).

Apesar das Escolas Normais experimentarem um desenvolvimento mais acelerado durante o período republicano, elas não possuíam ainda, até 1946, uma organização fundada em diretrizes estabelecidas pelo Governo Federal. Tal como o primário, o ensino normal era assunto da alçada dos Estados, ficando restritas às reformas, até então efetuadas, aos limites geográficos dos estados que as promovessem. A partir da Lei Orgânica do Ensino Normal promulgada no mesmo dia da Lei Orgânica do Ensino Primário, foram fixadas as normas para a implantação desse ramo do ensino em todo o território nacional. O decreto-lei 8530, de 2 de janeiro de 1946, que a instituía, oficializou como finalidade do ensino normal, "promover a formação do pessoal docente necessário às escolar primárias; habilitar administradores escolares destinados às mesmas escolas; desenvolver e propagar os conhecimentos e técnicas relativas à educação da infância" (Romanelli, 1984, p. 164). O ensino normal ficou subdividido em cursos de dois níveis: como curso de primeiro ciclo, passava a funcionar o curso de formação de regentes de ensino primário, com a duração de quatro anos, que funcionaria em escolas com o nome de Escolas Normais Regionais; e, como curso de segundo ciclo, continuavam a existir os cursos de formação de professor primário, com a duração de três anos, que funcionariam em estabelecimentos chamados Escolas Normais.

A Lei de Diretrizes e Bases da Educação Nacional - Lei № 4024, de 20/12/1961 - não trouxe soluções inovadoras para o ensino normal, conservando as grandes linhas da organização anterior, seja em termos de duração dos estudos ou de divisão em ciclos. Registra-se apenas a equivalência legal de todas as modalidades de ensino médio, bem como a descentralização administrativa e a flexibilidade curricular, que possibilitariam o rompimento da uniformidade curricular das escolas normais.

Manteve-se a preparação de professores regentes, nas chamadas Escolas Normais Ginasiais, com curso de 4 anos, e as Escolas Normais Colegiais, passaram e encarregar-se da habilitação dos professores primários, com 
duração de 4 anos. Os Institutos, por sua vez, continuaram a oferecer os mesmos cursos previstos pela legislação anterior, sendo-lhes acrescentada a possibilidade de habilitar professores para ministrar aulas em Escolas Normais dentro das normas estabelecidas para os cursos das Faculdades de Filosofia, Ciências e Letras (Gonçalves e Pimenta, 1992).

A partir de 1970, com a promulgação da Lei de Diretrizes e Bases para o ensino de $1^{\circ}$ e $2^{\circ}$ graus, Lei ํo 5692/91, o Curso de Magistério transformou-se em Habilitação Específica para o Magistério, em nível de segundo grau. Essa mudança extinguiu a formação de professores regentes, descaracterizando a estrutura anterior do curso. Assim "a formação de professores para a docência nas quatro séries do ensino de primeiro grau passou a ser realizada através de uma habilitação profissional, dentre as inúmeras outras que foram regulamentadas" (Gonçalves e Pimenta, 1992, p. 106). O currículo deveria apresentar um núcleo comum, obrigatório em âmbito nacional e um destinado à formação especial. Desapareciam os Institutos de Educação e a formação de especialistas e professores para o curso normal passou a ser feita exclusivamente nos cursos de Pedagogia.

Já com a promulgação da LDB ํo 9.394 de dezembro de 1996, o que assistimos foi a extinção da Escola Normal em nível secundário.

\section{A PROFISSIONALIZAÇÃO DO PROFESSOR DA EDUCAÇÃO INFANTIL}

Após esse breve histórico sobre o processo de formação docente é importante destacar nesse momento a situação do profissional que atua com a educação infantil - creche e pré-escola - 0 a $5^{7}$ anos. Como podemos observar houve preocupação, mesmo que mínima com a instrução do professor das séries iniciais, chamada de "tia", porém este que atua na $1^{\text {a }}$ etapa da educação básica - educação infantil - praticamente nunca foi mencionado uma atenção específica para sua formação.

\footnotetext{
${ }^{7}$ Com a regulamentação do Ensino Fundamental de 9 anos as crianças com 6 anos de idade passam a ser atendidas pelo Ensino Fundamental.
} 
No momento da Revolução Industrial a mulher sai para trabalhar, rompendo com a tradição familiar onde o homem trabalhava para sustentar a família e a mulher ficava em casa cuidando e educando os filhos. Hoje, crianças pequenas são obrigadas a deixarem o seio familiar e estarem em instituições enquanto suas mães trabalham nas fábricas.

No Brasil, com a crescente crise social e econômica a partir das décadas de 60 e 70, essa realidade se evidencia mais com o agravo de desemprego e miséria. A demanda por instituições de Educação Infantil constitui numa visão assistencialista, a busca de uma educação compensatória. As creches e préescolas são oferecidas para atender às crianças pobres, que necessitavam de assistência médica, higienista, alimentar e de puericultura. A partir daí, grandes questões surgem no que tange à formação dos profissionais que atuarão nesta área: Quem formará os profissionais da Educação Infantil? Como ocorrerá esta formação?

A Lei 4024/61 que trata de Diretrizes e Bases da Educação Nacional não fez nenhuma menção à Educação Infantil, em qualquer dos seus aspectos. Assim, pensando na corrente do tempo, há cerca de 40 anos atrás a questão da educação de crianças de 0 a 5 anos de idade ainda não tinha sido abordada pela legislação brasileira, muito menos a formação dos profissionais dessa área. Em 1971, dez anos depois, a Lei 5692/71 dedicou à Educação Infantil apenas um parágrafo, no art. 19, parágrafo $2^{\circ}$, declarando que : "Os sistemas de ensino velarão para que as crianças de idade inferior a sete anos recebam conveniente educação em escolas maternais, jardins de infância e instituições equivalentes".

Esse dispositivo legal apesar de mencionar a importância de uma educação específica para as crianças menores de 7 anos, não abordou a questão de maneira profunda como deveria ser, visto a especificidade desta educação, tratando a questão de uma forma muito genérica, não comprometendo-se com a responsabilidade de preparar os profissionais que atuavam na Educação Infantil, não cogitando a formação destes. 
Ao estar previstos na Carta Magna o atendimento às crianças de 0 a 6 anos e seu reconhecimento como sujeitos de direitos, isto passou a requerer novas regulamentações, o que culminou na promulgação do Estatuto da Criança e do Adolescente (ECA) em 1990 e na atual LDB, Lei no 9394/96.

Há que se ficar atento à qualidade da formação veiculada pelas faculdades particulares de Ensino Normal Superior da região e de todo país e aos projetos do governo - Projeto Veredas. Propor educação à distância como formação para professores em exercício, é prova concreta da morosidade de parte das políticas públicas de nosso país. A educação à distância deveria ser uma forma de complemento da capacitação profissional e não um recurso primeiro para tal fim. Enfatizo mais uma vez que a formação superior deve ocorrer em instituições, tais como as universidades.

É importante que a luta pela volta dos cursos de formação em nível médio não deve ofuscar a busca da formação superior com habilitação em Educação Infantil. Por razões históricas, que todos conhecem, o acesso à cursos superiores é para poucos no Brasil, é desejável que essa oferta seja prioritária, mesmo porque, em se tratando de educar e cuidar de crianças de 0 a 6 anos, é necessário um profissional bem preparado.

LANTER (1999, p. 137), criticando as políticas públicas em prol da qualificação de profissionais da Educação Infantil diz:

A questão da formação dos professores representa para a educação infantil, dente outros aspectos, questão fundamental para 0 reconhecimento desse segmento como instância educativa e também para a sua qualidade. Sendo assim, percebemos que a ausência de políticas voltadas para o profissional de educação infantil favorece e acelera o descompromisso como o poder público da criança de 0 a 6 anos no país, bem como despolitiza a ação dos profissionais de educação infantil.

Defender o magistério superior para educação infantil, em universidade é defender a profissionalização do magistério e para tanto faz-se necessária, a implementação de políticas públicas que garantam a valorização e a formação continuada em serviço desses profissionais. A formação dos profissionais para Educação Infantil torna-se um desafio para educadores, sociedade e Estado, 
haja visto que a responsabilidade é de todos. Para isso, os cursos de formação devem estar atentos ao currículo que capacitará esse profissional, abrangendo as premissas do cuidar e educar. Uma competência técnica e um compromisso político, também devem ser acoplados com o saber ser. Exatamente no saber ser é que estão as características mais pertinentes do educador infantil. Trabalhar com crianças significa gostar delas e do que elas fazem.

A herança histórica desses séculos sem uma educação sistemática e de qualidade faz com que as mudanças ocorram lentamente. Reverter esse quadro é difícil, mas não impossível.

\section{CONSIDERAÇõES FINAIS}

Conforme colocado no texto, as primeiras Escolas Normais no Brasil foram fundadas no período da Regência e nas duas primeiras décadas do Segundo Reinado.

De um modo geral, a evolução do Ensino Normal foi lenta e por muitos anos limitada a oferecer ao professor uma formação à curto prazo. Até os primeiros cinquenta anos do Império as Escolas Normais não possuíam ainda respaldo na educação brasileira. A partir da década de 20, a Escola Normal começa a sofrer transformações. De acordo com Nagle (1990), a preocupação com a Escola Normal inicia-se como resultado da expansão da escola primária iniciada pelo entusiasmo educacional, intensificando-se com o otimismo pedagógico que se desenvolve em relação à escola primária, infiltrando-se no domínio da Escola Normal.

Cumpre ressaltar ainda, que a profissionalização docente no Brasil aconteceu em decorrência das profundas transformações econômicas e sociais, pertinentes à nova fase da produção capitalista monopolista, que aqui se implantava ao término do século XIX, início do século XX. Dando início ao processo de industrialização brasileira, com a substituição da mão-de-obra escrava pelo trabalho assalariado, o novo modelo econômico possibilitou o 
aparecimento da classe operária em nossa sociedade, bem como 0 alargamento da classe média, em decorrência da mudança do eixo econômico do setor agrícola latifundiário para o agrícola-industrial-exportador (Romanelli, 1978).

Bruschini (1988), referindo-se ao processo de sistematização do ensino brasileiro, chama a atenção para sua recente existência, posto que, foi somente no século passado, após a Independência, que nosso ensino, pelo menos a nível dos projetos e das leis, se tornou gratuito e extensivo a todos.

Com o advento da República, a profissionalização do magistério teve uma transformação substancial. Na busca da sistematização do ensino, o Estado normatizou o trabalho do mestre-escola, passando a pagar seu salário, transformando-o em funcionário público. Antes disso, os mestres que se dedicavam ao ensino das primeiras letras, reconhecidos e pagos por suas comunidades, faziam-no de uma maneira autônoma, na intimidade de seus lares, optando por métodos e programas singulares (Cristo, 1994).

Coelho (1998) ressalta o fato da atividade educacional, até então, ser exercida sem o cumprimento de qualquer exigência legal. Segundo ele, "o professor era, geralmente, egresso de outras profissões, havendo em exercício pessoas com as mais diferentes formações, autodidatas, militares, membros de irmandades religiosas e estudantes ou diplomados de escolas superiores." (p.61).

A busca dos ideais republicanos fez crescer as pressões quanto à necessidade de ampliação das oportunidades educacionais. Neste sentido, Nagle (1990) afirma:

\footnotetext{
A escolaridade era tratada por homens públicos e por intelectuais que, ao mesmo tempo, eram "educadores", num tempo em que assuntos educacionais não constituíam, ainda, uma atividade suficientemente profissionalizada. Apenas na década final da primeira república a situação vai ser alterada, com o aparecimento do "técnico" em escolarização, a nova categoria profissional: este é que vai dar por diante tratar, com quase exclusividade, dos assuntos educacionais (p.102).
}

Além disso, alarga-se o grupo de profissionais interessados no problema da educação, surgindo os primeiros profissionais da educação preocupados com a 
qualidade do ensino, destacando-se os profissionais" do jornalismo como Fernando de Azevedo, do ensino normal como Lourenço Filho e os com formação específica em educação como Anísio Teixeira.

Tendo o processo de profissionalização da atividade do magistério se iniciado nos anos 20, podemos dizer que os professores tiveram seu momento de ascensão social a partir da década de 30 , quando o consequente desenvolvimento e a complexificação da sociedade brasileira estimularam o crescimento da demanda pela educação. A crença na educação, como possibilitadora de igualdade de oportunidade para todos veiculou na sociedade uma intensa busca pela escolarização, como se a solução para as contradições e antagonismos da sociedade capitalista pudesse repousar em uma mudança de atitude mental. (Gandin, 1995).

Em 1931, foi publicada a lei que dá início à regulamentação da profissão, com a criação do Registro Profissional, que se constituiu em objeto de acentuadas discussões na sociedade, mobilizando, sobretudo os professores (Ferreira, 1998).

Nos anos 40, o populismo da era Vargas iria se manifestar pela intervenção do Estado como mediador das lutas de classe e por sua crescente burocratização. Foram agilizadas reformas ministeriais, criação de secretarias e órgãos planejadores. A preocupação com a educação nacional norteava-se para 0 atendimento das demandas da classe média urbana - mobilizada para a extensão vertical da Educacão, na exigência pelo ensino secundário - ao mesmo tempo em que a educação era utilizada como forma de repressão aos movimentos populares. A exigência da assinatura da carteira profissional e 0 registro da profissão no Ministério do Trabalho, o qual passa a fiscalizar o cumprimento dos dispositivos legais que regulamentam a profissão, traçam um novo perfil profissional para a atividade do magistério.

À medida que as transformações econômicas, ligas à modernização do país, impunham novas exigências à profissão, e que a educação foi sendo atrelada às concepções desenvolvimentistas, modificava-se substancialmente as 
relações no interior da escola. A crescente burocratização decorrente do desejo de maior controle dos currículos e programas, exercidas pelos burocratas educacionais, contribuíram para a reificação do professor, afastando-o gradativamente da condição de sujeito de sua própria prática.

Percorrendo o passado e olhando para o presente, percebemos os altos e baixos da formação docente, suas fragilidades, seus caminhos e descaminhos. A afirmação profissional dos professores é um percurso repleto de lutas e de conflitos, de hesitações e de recuos (Nóvoa, 1995, p.21). Vemos que muitos dos problemas vividos hoje têm sua raiz em algum lugar na história da profissionalização do magistério.

Portanto, apesar de todas as iniciativas registradas nas duas últimas décadas, o esforço ainda se configura bastante pequeno no sentido de investir de modo consistente e efetivo na qualidade da formação docente.

Segundo Nóvoa, (1995, p.26) "a formação de professores precisa ser repensada e reestruturada como um todo, abrangendo as dimensões da formação inicial, da indução e da formação continua". Pouco adianta preocupar-se com a formação a nível superior sem que depois essa capacitação dê continuidade. Nesta perspectiva Marques (2000, p.210) acentua,

[...] deve o educador egresso da universidade voltar a ela, sempre e de novo, ou melhor, deve provocá-la a que vá a seus locais de trabalho e a seus encontros no seio da profissão, para que eles, os educadores, possam com ela redescobrir-se e interrogar a si mesmos e para que possa ela, a universidade, reaprender com eles o que lhes ensinou.

E ainda ressalta que a capacitação - qualificação - do profissional do magistério deve ser constante e em serviço "formação humana na forma do exercício ativo e compromissado da profissão" (Marques, 2000, p.12).

Para finalizar, destacamos que ao educar uma nação, necessariamente, tem que se trabalhar com transformações e não com repetições. Para que essas 
ocorram de maneira efetiva, a formação do profissional para a educação infantil e demais níveis deve ser considerada como uma das prioridades das políticas públicas e das lutas para uma educação de qualidade no Brasil.

\section{REFERÊNCIAS BIBLIOGRÁFICAS}

AZEVEDO, Fernando. A cultura brasileira. 4ํe., Universidade de Brasília, 1963.

BARROS, Roque S. Maciel de. A ilustração brasileira e a ideia de universidade. São Paulo: Convívio: Editora da Universidade de São Paulo.

BRASIL, Lei o 9394 de 20 de dezembro de 1996. Diretrizes e Bases para a Educação Nacional. DOU de 23 de dezembro de 1996.

BRZEEINSKI, Iria (org). LDB Interpretada: diversos olhares se entrecruzam. São Paulo: Cortez, 1997.

FERREIRA, Lenira Weil. As contribuições do sistema educacional no Brasil Colônia. In: A paixão de aprender. SME-PMPA, № 12, abr2000, 79-87

GONÇALVES, Carlos Luiz. PIMENTA, Selma Garrido. Revendo o ensino de 2o grau: propondo a formação de professores. São Paulo: Cortez, 1992.

LANTER, Ana Paula. A política de formação do profissional de Educação Infantil: os anos 90 e as diretrizes do MEC diante da questão. In: KRAMER, Sonia; LEITE, M ${ }^{a}$ Isabel; NUNES, Mำ Fernanda e GUIMARÃES, Daniela (orgs.). Infância e educação infantil. Campinas/SP: Papirus, 1999.

MARQUES, Mário Osório. Formação do profissional da educação. ljuí/RS: Ed. UNIJUI, 2000.

NAGLE, Jorge. Educação na Primeira República. In: BORIS, Fausto (org.). História Geral da Civilização Brasileira. Tomo III: O Brasil Republicano V.2. Sociedade e Instituições (1889-1930) Rio de Janeiro: Ed Berton S/A, 1990.

NÓVOA, Antônio. Para o estudo sócio-histórico da gênese e desenvolvimento da profissão docente. In: Teoria e educação. Porto Alegre/RS: Pannonica, V. 04, 1991, 109-119.

NÓVOA, Antônio. Formação de professores. In: Vidas de professores. Portugal: Porto, 1992, 13-30.

NÓVOA, Antônio. O processo histórico de profissionalização do professorado. In: . (Org.) Profissão professor. 2ªed. Porto: Porto, 1995, p.13-33. 
RIBEIRO, $M^{a}$ Luisa $S$. História da educação brasileira: a organização escolar. 14ํe.Campinas/SP: Autores Associados, 1995.

ROMANELLI, Otaíza de Oliveira. História da educação no Brasil (19301973). Petrópolis/RJ: Vozes, 1984.

SILVA, Rose Neubauer e al. Formação de professores no Brasil: um estudo analítico e bibliográfico. São Paulo: Fundação Carlos Chagas, REDUC, 1991.

SOUZA, Paulo Renato. Decreto № 3.276 de 6 de dezembro de 1999. In: Educação, sociedade e formação de profisionais da educação: políticas e tendências da educação. Campinas/ SP: Caderno Cedes, número especial.

TANURI, Leonor Ma . História da formação de professores. In: Revista Brasileira de Educação: $\mathbf{5 0 0}$ anos de Educação. Editores Associados, ํo 14, mai/jun/jul/ago.2000, 61-88.

VILLELA, Heloisa de O. S. O mestre-escola e a professora. In: LOPES, E.; FARIA FILHO, L.;VEIGA, Cyntia (org.). 500 anos de educação no Brasil. $2^{\mathrm{a}}$ ed. Belo Horizonte/MG: Autêntica, 2000, 95-134.

BRASIL. Estatuto da Criança e do Adolescente. Lei 8069, 13 de julho de 1990. 